nephron

Practice
Nephron 2019;143:17-23

DOI: $10.1159 / 000494390$
Received: June 30, 2018

Accepted after revision: October 9, 2018

Published online: January 9, 2019

\title{
Mercapturate Pathway in the Tubulocentric Perspective of Diabetic Kidney Disease
}

\author{
Clara Gonçalves-Dias ${ }^{a}$ Judit Morello ${ }^{b}$ M. João Correia ${ }^{a}$ Nuno R. Coelho ${ }^{a}$
} Alexandra M.M. Antunes ${ }^{b}$ Maria Paula Macedo ${ }^{a, c, d}$ Emília C. Monteiro ${ }^{a}$

Karina Soto $^{a}$ e Sofia A. Pereira ${ }^{a}$

${ }^{a}$ CEDOC, Chronic Diseases Research Centre, NOVA Medical School|Faculdade de Ciências Médicas, Universidade NOVA de Lisboa, Campo dos Mártires da Pátria, Lisboa, Portugal; ${ }^{b}$ Centro de Química Estrutural (CQE), Instituto Superior Técnico, Universidade de Lisboa, Av. Rovisco Pais, Lisboa, Portugal; ' $P$ Portuguese Diabetes Association Education and Research Center (APDP-ERC), Lisboa, Portugal; d Departamento de Ciências Médicas, Universidade de

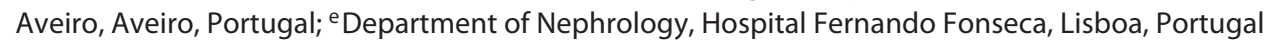

\section{Keywords}

Cysteine-S-conjugates - Diabetic nephropathy · Mercapturic acids $\cdot N$-Acetyltransferase $8 \cdot$ Renal proximal tubular cells

\begin{abstract}
Background: The recent growing evidence that the proximal tubule underlies the early pathogenesis of diabetic kidney disease (DKD) is unveiling novel and promising perspectives. This pathophysiological concept links tubulointerstitial oxidative stress, inflammation, hypoxia, and fibrosis with the progression of DKD. In this new angle for DKD, the prevailing molecular mechanisms on proximal tubular cells emerge as an innovative opportunity for prevention and management of DKD as well as to improve diabetic dysmetabolism. Summary: The mercapturate pathway (MAP) is a classical metabolic detoxification route for xenobiotics that is emerging as an integrative circuitry detrimental to resolve tubular inflammation caused by endogenous electrophilic species. Herein we review why and how it might
\end{abstract}

underlie DKD. Key Messages: MAP is a hallmark of proximal tubular cell function, and cysteine-S-conjugates might represent targets for early intervention in DKD. Moreover, the biomonitoring of urinary mercapturates from metabolic inflammation products might be relevant for the implementation of preventive/management strategies in DKD.

(C) 2019 S. Karger AG, Basel

Proximal tubule underlies the early pathogenesis of diabetic kidney disease (DKD) [1]. The defined pathophysiological tubulocentric concept of DKD identifies the unique early growth phenotype of the proximal tubule as a potential target for the prevention of early tubular hyperreabsorption and glomerular hyperfiltration, but perhaps more importantly, its early link to tu-

Contribution from the CME Course of the DIABESITY Working Group of the ERA-EDTA, Lisbon, November 24-25, 2017.

\section{KARGER}

๑) 2019 S. Karger AG, Basel

E-Mail karger@karger.com

www.karger.com/nef
Sofia de Azeredo Pereira, PhD

CEDOC, Chronic Diseases Research Centre, NOVA Medical School|Faculdade de Ciências Médicas, Universidade NOVA de Lisboa, Campo dos Mártires da Pátria 130, PT-1169-056 Lisboa (Portugal)

E-Mail sofia.pereira@nms.unl.pt 


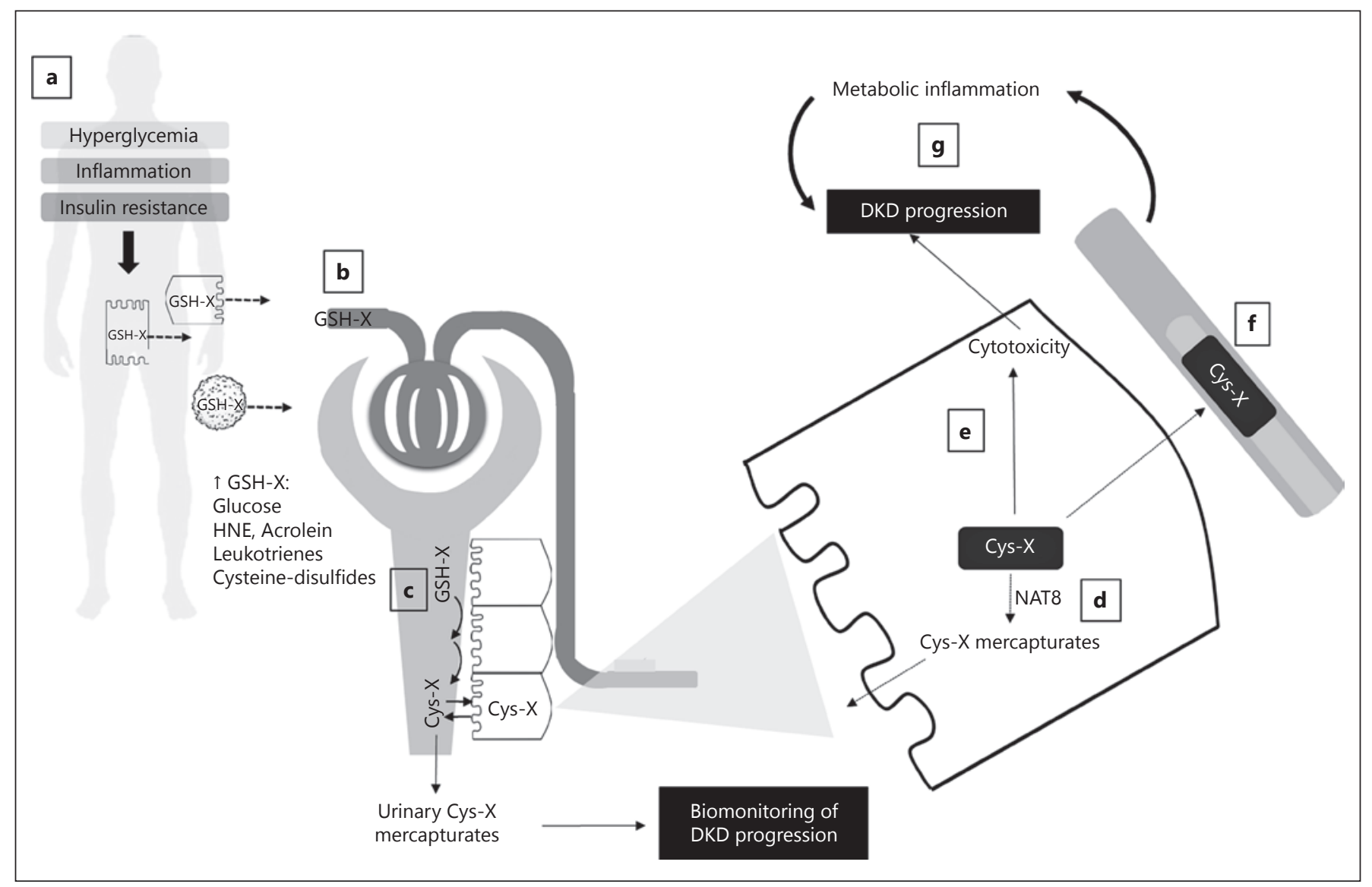

Fig. 1. Mechanistic hypothesis of MAP role in the tubulocentric view of diabetic kidney disease (DKD) billed up on literature review herein presented. (a) GSH-S-conjugates (GSH-X) of electrophiles increase in inflammatory conditions in both immune and nonimmune cells, (b) being excreted into the bloodstream and have a short half-life due to its rapid (c) metabolization at the external apical membrane of proximal tubular cells. The generated
cysteine-S-conjugate (Cys-X) may have one of 3 fates. (d) They may be detoxified by $N$-acetyltransferase 8 (NAT8), generating mercapturates that are eliminated in urine, (e) they may be bioactivated to highly cytotoxic species or (f) they may be reabsorbed into the bloodstream, $(\mathbf{g})$ perpetuating metabolic inflammatory processes and DKD progression. bulointerstitial inflammation, fibrosis, oxidative stress, hypoxia, and kidney dysfunction [2]. The present review aims to include the mercapturate pathway (MAP) in the roadmap of tubulocentric concept of DKD.

\section{The MAP Is a Hallmark of Proximal Tubular Cell Function}

The MAP has been associated to chronic kidney disease (CKD) and is mainly expressed in renal proximal tubular cells [3-5], predominantly in cortical regions [3, 6]. MAP was described as a metabolic detoxification circuitry for electrophilic species generated under inflammatory and oxidative conditions [7] (Fig. 1).
In fact, MAP enzymes have endogenous functions in the kidney and may have evolved to detoxify endogenous reactive toxic intermediates rather than only xenobiotics [8-10]. Endogenous compounds undergoing MAP include leukotrienes [6], glucose [11], catecholamines [12], cysteine-disulfides [13], and lipid peroxidation products $[14,15]$, whereas paracetamol [16] and cisplatin [17] are examples of xenobiotics.

Any cell under inflammatory or oxidative conditions can produce $\gamma$-glutamylcysteinylglycine (GSH) conjugates upon the intracellular conjugation of GSH with an electrophile, generating covalent glutathione-S-conjugates, also denominated as GSH-electrophile adducts (GSH-X) [18] (Fig. 1a). However, as cells are not able to catabolize these conjugates, they are excreted to the 
bloodstream (Fig. 1b). Their permanence in the bloodstream is transitory $[11,19]$, as they undergo MAP (Fig. 1c). MAP is majorly expressed in proximal tubular cells of kidney cortex $[3,6]$ and includes 3 enzymes that act in consecutive steps. First, $\gamma$-glutamiltranspeptidase, that is the only enzyme known to initiate the breakdown of GSH-X, generates cysteinyl-glycine-S-conjugates. Those are cleaved by cysteinyl-glycine dipeptidase or, to a minor extent, aminopeptidase- $\mathrm{M}$, to form cysteine-Sconjugates (Cys-Xs). All ectoenzymes are majorly present at the brush border membrane of proximal tubular cells $[3,5,20,21]$. However, the enzymes are also present in other tissues as liver, small intestine, lung, brain, spleen, and pancreas (for review see [22]), enabling Cys-X formation that can be delivered to the kidney by glomerular filtration [22].

The formed Cys-X has significantly higher half-life than the precursor and is the plausible responsible for biological effects $[11,19]$. The effects of Cys-X have been underestimated, probably because MAP has been classically considered a detoxification route for xenobiotics. Although, it is known that cysteine-cisplatin is more toxic to tubular cells than cisplatin [17]. Another example, the Cys-X of paracetamol is related to its nephrotoxicity, but not hepatotoxicity [23].

The information available regarding the precise transporter involved in the entrance of Cys-Xs into tubular cells in man is, as far as we known, still to be identified. There is evidence in vitro and in animal models that Cys$\mathrm{X}$ enter the proximal tubular cells by sodium-dependent and independent transepithelial transport across both basolateral and brush border membranes, including through organic anion transporters (for a review see [22]).

When Cys-X go into the proximal tubular cell [24], they may undergo into one of 3 fates. First, they can be a substrate for $\mathrm{N}$-acetyltransferase 8 (NAT8) that is predominantly expressed in the microsomes [6], producing an $N$-acetylcysteine- $S$-conjugate also known as a mercapturate [6]. The $\mathrm{N}$-acetyl moiety of mercapturates confers a polar, water-soluble, and anionic character, making them more prone to elimination in urine $[6,24]$ (Fig. 1d). Hence, urinary mercapturates of several xenobiotics have been used for biomonitoring purposes in environmental and occupational exposure [25]. Thereby, the generation of mercapturates is considered a feature of proximal tubular cells $[26,27]$.

On the other hand, Cys-Xs in the proximal tubular cell might also undergo $\beta$-elimination through $\beta$-lyase activity, forming reactive intermediates that have been strongly related to kidney injury $[27,28]$ (Fig. 1e). $\beta$-Lyases cat- alyze the cleavage of Cys- $\mathrm{X}$ into a potentially toxic thiol (sulfur)-containing fragment and dehydroalanine, which very rapidly hydrolyzes to ammonia and pyruvate [22]. In rat, $\beta$-lyase is present mainly in cytosol and, to a lesser extent, in mitochondria. Differently, in man, a considerable $\beta$-lyase activity was found in microsomes. Studies performed in rat have shown that this activity is absent in the glomeruli and distal tubule. Regarding distribution in the proximal tubule, there are conflicting data on the segments involved $[29,30]$. The involvement of $\beta$-lyasemediated bioactivation of Cys-X in nephrotoxicity has been demonstrated for several toxicants (for a review see [22] and [31]).

In accordance, a nephroprotective role has been attributed to the tubular enzyme NAT8 that promotes the urinary elimination of these compounds [6], counteracting $\beta$-lyase activity, avoiding their reabsorption into the bloodstream and promotion of systemic metabolic inflammation (Fig. 1f). Evidence supporting that NAT8 is nephroprotective came majorly from association studies [3, 32-34]. The study of Juhanson et al. [32] included 137 controls and 157 hypertensive patients with and without nephropathy and identified single-nucleotide polymorphisms in the promoter region of NAT8 associated with systolic blood pressure and renal function (estimated glomerular filtration rate [eGFR]). In particular, minor alleles (of the same single-nucleotide polymorphisms) were found to be related with lower blood pressure and higher eGFR. The authors hypothesized that this effect was explained by the reduced susceptibility of the minor alleles to transcriptional suppression, hence guarantying the availability of NAT8. Chambers et al. [3] reported an association between common genetic variations in NAT8 gene and creatinine, cystatin c, Egfr, and CKD in a population of 16,626 Europeans. On the same year, the CKDGen consortium performed a meta-analysis of genome-wide association data in 67,093 Caucasian individuals and found that NAT8 was a susceptibility locus for reduced renal function, estimated by eGFR obtained separately with both creatinine and cystatin c and also CKD [34]. Moreover, NAT8 was the only kidney locus identified that was associated with eGFR in all 3 different genome-wide scans performed in 9,049 European Americans [33].

More recently, the role of NAT8 has been investigated in regenerative processes of the kidney tubular cell. Omata et al. [35] found a reduction of NAT8 transcript levels upon transforming growth factor-1 exposure using an in vitro model of dedifferentiation/reepithelization of human proximal tubular cells. This cytokine promoted cell 
dedifferentiation, an event initiator of repair process in early stages of renal injury. Transforming growth factor-1 withdrawing after dedifferentiation did not prevented reepithelization in NAT8 knock-down cells. The authors suggested that the recovery process may be independent of the activity of NAT8. In addition, the difficulty in developing NAT8 knockout rats [36] and absence of tools to pharmacologically address NAT8 hinders to get hard evidence on the nephroprotective role of this enzyme.

Cys-X have primarily vascular and hemodynamic properties [37], being potent vasoconstrictors [38-40] with an ability to enhance the permeability of the postcapillary venules [41]. Therefore, the elimination of these conjugates could have nephroprotective consequences.

It has been shown that Cys-Xs are involved in glucosestimulated insulin secretion [42] and have pro-inflammatory [12], cytotoxic [17, 23, 43, 44], and immunogenic [45] properties (Fig. 1g), all processes involved in the development of DKD.

Thus, MAP is a hallmark of proximal tubular cell function, and NAT8 activity is nephroprotective by avoiding systemic accumulation of Cys-Xs.

\section{Cys-Xs Might Represent Targets for DKD}

The formation of cysteinyl-leukotrienes (CysLTs) is the best described example among endogenous compounds generated through MAP $[6,46]$. CysLTs are products of arachidonic acid metabolism and key mediators of inflammatory conditions [47-49], which are responsible for enhancing the conversion of arachidonic acid into the short-lived LTA4 [50]. LTA4 is further conjugated with GSH to yield a glutathione-S-conjugate (LTC4) that is effluxed from cells. Extracellular LTC4 undergoes a two-step catabolic process originating, respectively, the cysteinyl-glycine-S-conjugate (LTD4) and Cys-X (LTE4) through the MAP $[47,48]$. These compounds are generally termed CysLTs, although these denominations fully suit only for LTE4, which has the longer half-life [19]. DKD was associated with lower urinary LTE4 concentrations [51]. A multivariate analysis revealed that only eGFR was an independent predictor of urinary LTE4 concentrations. Currently, there is no evidence to support if this implicates a role for circulating LTE4 in its own urinary excretion, a decrease in its renal formation or an increase in its elimination as an $\mathrm{N}$-acetylLTE4 rather than in the LTE4 form.

As the best of the author's knowledge, this association study was the only one investigating the effect of LTE4 in
DKD. Although, there are descriptions in diabetes and kidney disease separately; for instance, the synthesis and release of CysLTs by the kidney have been described [44, 52]. The role of leukotrienes in kidney diseases was recently reviewed [53] and was demonstrated that they are able to reduce real blood flow and GFR by triggering vasoconstriction. On the other hand, they can promote immune and nonimmune-mediated kidney damage and oxidative intracellular stress [44]. The selective inhibition of CysLTs is being investigated in several models of kidney disease [53], but their nephroprotection ability in man is still unknown.

Under inflammatory conditions, the temporal changes in urinary CysLTs elimination were paralleled with their biosynthesis enzyme activity in renal cortical microsomes. Urinary CysLTs levels increased in initial stages and decreased along kidney disease progression, supporting an early role for CysLTs in the development of subsequent functional changes [54].

CysLTs were reported to promote angiotensin II release, increase mean arterial pressure, decrease cardiac output, renal blood flow, and eGFR $[55,56]$. Additionally, several studies showed the association of CysLTs biosynthesis with drug-induced nephrotoxicity [53]. Lastly, in an in vitro approach, aristolochic acid I-induced tubular injury was associated with CysLTs release, via ERK pathway activation [57].

Regarding diabetes, it has been reported the effect of CysLTs as constrictors of the coronary vasculature in alloxan-diabetic rat $[58,59]$ and streptozotocin models, but not in fructose fed or insulin-treated diabetic animals [60, $61]$. On the other hand, the increased urinary excretion of LTE4 has been associated with diabetes [60, 62], suggesting that hyperglycemia activates arachidonic acid metabolism and consequent CysLTs formation. Intensive glycemic control is able to reduce its elimination in patients with type 1 diabetes, although no changes were observed in type 2 diabetes $[60,62,63]$.

Glucose can also generate cysteinyl-S-conjugates that are far more stable than GSH-glucose and glucose-cysteine urinary levels are higher in patients with diabetes [11].

Besides CysLTs and glucose-cysteine, another class of Cys-Xs is cysteine-disulfides. In a model of secondary hypertension and insulin resistance, the levels of cysteinedisulfides in kidney increased in early phases of disease [64].

While the available evidence is mainly focused on CysLTs, there are other endogenous Cys-Xs, which levels are changed in inflammatory conditions. Even though, 
several aspects on CysLTs are missing such as their synthesis and mechanism of action in immune and non-immune-mediated kidney damage on diabetic milieu. Also, the receptor responsible for LTE4 effects is still to be clarified [65]. The methodology employed for the quantification of MAP $S$-conjugates should allow the discrimination between GSH-S-conjugates, Cys-Xs, and mercapturates in serum and urine and their relation with DKD.

\section{Urinary Mercapturates for Biomonitoring in DKD}

Based on the association of NAT8 and kidney function [32], urinary mercapturates may be used as a hallmark of proximal tubular cells capability to detoxify Cys-X. This enzyme is highly and almost exclusively expressed in proximal tubular cells [3]. In addition, mercapturates are measured in urine, rendering them feasible for biomonitoring purposes $[13,25]$.

There has been an association between mercapturates of endogenous compounds and kidney disease. Decreased urinary levels of mercapturates of cysteine-disulfides were associated with kidney disease progression in HIVinfected patients [13].

The urinary elimination of the mercapturate $\mathrm{N}$-acetylLTE4 is increased in inflammatory conditions [54] and with cyclosporine A treatment [66].

Acrolein is a dietary, environmental pollutant and lipid metabolism-derived electrophile associated to diabetic dysmetabolism and 2 of its urinary mercapturates were associated with diabetes and insulin resistance [15]. Urinary acrolein mercapturates are increased in diabetic patients and are related to glycemic control parameters, but not with lipid metabolism nor albumin to creatinine ratio [67].

Another electrophile that undergoes the MAP is 4-hydroxynonenal (HNE), a normal constituent of mammalian cell membranes, considered a highly potent reactive species that promotes propagation and amplification of the effects elicited by free radicals. The evaluation of HNE metabolism in vivo can be performed by monitoring urinary HNE mercapturate that is decreased in patients with impaired glucose tolerance [14].

In summary, there is evidence on the biomonitoring of mercapturates of endogenous compounds in man and its relation to metabolic control in diabetes and also to kidney disease. Although there are dozens of endogenous compounds undergoing MAP [46], information is still missing such as the contribution of each particular mercapturate in DKD.

MAP Underlies DKD
Herein, we focused on Cys-X that have been associated to DKD, kidney disease, and/or diabetes. We found that LTE4, cysteinyl-glucose, and cysteine-disulfides have been associated to the pattern of Cys-X associated to these conditions. However, the literature review-driven hypothesis herein built might not be exclusive for diabetes. For instance, LTE4 is known to be associated to DKD [51] and to other inflammatory diseases such as coronary artery disease [68], cardiac ischemia [69], asthma [70], as well as with obesity and hypoxia severity related to sleep apnea [71]. Even though, cysteinyl-glucose was only reported in patients with diabetes [11], and on the basis that these compounds have in common the detoxification by the proximal tubular cells as mercapturates that might motivate a tubulocentric perspective for other inflammatory conditions.

\section{Summary and Perspectives in Mercapturate Involvement in DKD}

The inability of proximal tubular cells to detoxify cysteinyl-S-conjugates, through NAT8 activity, might perpetuate metabolic inflammation and dysmetabolism and supports that MAP underlies the tubulocentric perspective of $\mathrm{DKD}$. This dysfunction in proximal tubular cell activity can be monitored through the quantification of mercapturates of cysteinyl-S-conjugates in urine.

A better understanding of MAP impairment triggering early $\mathrm{DKD}$ is necessary. Such knowledge may help to find out new therapeutic approaches and strategies for early prediction and biomonitoring of DKD.

\section{Disclosure Statement}

The authors declare no conflicts of interest.

\section{Funding Sources}

iNOVA4Health - UID/Multi/04462/2013, a program financially supported by Fundação para a Ciência e Tecnologia/Ministério da Educação e Ciência, through national funds and co-funded by FEDER under the PT2020 Partnership Agreement is acknowledged (Ref: 201601-02-021). Authors supported by Fundação para a Ciência e a Tecnologia (FCT - Portugal): PD/ BD/105892/2014 for CGD; 022125 for JM; SFRH/BD/130911/2017 for MJC; PD/BD/114257/2016 for NRC; Programa Operacional Potencial Humano and the European Social Fund (IF/01091/2013) for AMMA. 


\section{References}

1 Zeni L, Norden AGW, Cancarini G, Unwin RJ: A more tubulocentric view of diabetic kidney disease. J Nephrol 2017;30:701-717.

2 Vallon V: The proximal tubule in the pathophysiology of the diabetic kidney. Am J Physiol Regul Integr Comp Physiol 2011;300: R1009-R1022.

3 Chambers JC, Zhang W, Lord GM, van der Harst P, Lawlor DA, Sehmi JS, et al: Genetic loci influencing kidney function and chronic kidney disease. Nat Genet 2010;42:373375.

4 Datta SK, Kumar V, Pathak R, Tripathi AK, Ahmed RS, Kalra OP, et al: Association of glutathione S-transferase M1 and T1 gene polymorphism with oxidative stress in diabetic and nondiabetic chronic kidney disease. Ren Fail 2010;32:1189-1195.

5 De Carvalho JA, Piva SJ, Hausen BS, Bochi GV, Kaefer M, Coelho AC, et al: Assessment of urinary $\gamma$-glutamyltransferase and alkaline phosphatase for diagnosis of diabetic nephropathy. Clin Chim Acta 2011;412:14071411.

6 Veiga-da-Cunha M, Tyteca D, Stroobant V, Courtoy PJ, Opperdoes FR, Van Schaftingen E: Molecular identification of NAT8 as the enzyme that acetylates cysteine $\mathrm{S}$-conjugates to mercapturic acids. J Biol Chem 2010;285: 18888-18898.

7 Habig WH, Pabst MJ, Jakoby WB: Glutathione $\mathrm{S}$ transferases. The first enzymatic step in mercapturic acid formation. J Biol Chem 1974;249:7130-7139.

8 Huber M, Müller J, Leier I, Jedlitschky G, Ball HA, Moore KP, et al: Metabolism of cysteinyl leukotrienes in monkey and man. Eur J Biochem 1990;194:309-315.

9 Bernstrom K, Hammarstrom S: Metabolism of leukotriene E4 by rat tissues: formation of $\mathrm{N}$-acetyl leukotriene E4. Arch Biochem Biophys 1986;244:486-491.

10 Deol R: Substrate specificity of human Nacetyltransferase 8 for aromatic cysteine conjugates. Master Thesis 2015. p 4.

11 Szwergold BS: Alpha-Thiolamines such as cysteine and cysteamine act as effective transglycating agents due to formation of irreversible thiazolidine derivatives. Med Hypotheses 2006;66:698-707.

12 Magnay JL, Tong J, Drangova R, Baines AD: Production of cysteinyl-dopamine during intravenous dopamine therapy. Kidney Int 2001;59:1891-1898.

13 Dias C, Campos P, Diogo L, Trigo D, Correia MJ, Lemos A, et al: Kidney disease progression in HIV-infected patients related with the detoxification of endogenous electrophilic species. Nephrol Dial Transplant 2017;32: iii540-iii541.

14 Ntimbane T, Krishnamoorthy P, Huot C, Legault L, Jacob SV, Brunet S, et al: Oxidative stress and cystic fibrosis-related diabetes: a pilot study in children. J Cyst Fibros 2008;7: 373-384.
15 Feroe AG, Attanasio R, Scinicariello F: Acrolein metabolites, diabetes and insulin resistance. Environ Res 2016;148:1-6.

16 Jian W, Yao M, Zhang D, Zhu M: Rapid detection and characterization of in vitro and urinary $\mathrm{N}$-acetyl-L-cysteine conjugates using quadrupole-linear ion trap mass spectrometry and polarity switching. Chem Res Toxicol 2009;22:1246-1255.

17 Townsend DM, Deng M, Zhang L, Lapus MG, Hanigan MH: Metabolism of cisplatin to a nephrotoxin in proximal tubule cells. J Am Soc Nephrol 2003;14:1-10.

18 Ballatori N, Krance SM, Notenboom S, Shi S, Tieu K, Hammond CL: Glutathione dysregulation and the etiology and progression of human diseases. Biol Chem 2009;390:191-214.

19 Kanaoka Y, Boyce JA: Cysteinyl leukotrienes and their receptors; emerging concepts. Allergy Asthma Immunol Res 2014;6:288295.

20 Hirota T, Nishikawa Y, Tanaka M, Fukuda K, Igarashi T, Kitagawa $\mathrm{H}$ : Localization of dehydropeptidase-I, an enzyme processing glutathione, in the rat kidney. J Biochem 1987;102: 547-550.

21 Kempson SA, McAteer JA, Al-Mahrouq HA, Dousa TP, Dougherty GS, Evan AP: Proximal tubule characteristics of cultured human renal cortex epithelium. J Lab Clin Med 1989; 113:285-296.

22 Commandeur JN, Stijntjes GJ, Vermeulen NP: Enzymes and transport systems involved in the formation and disposition of glutathione S-conjugates. Role in bioactivation and detoxication mechanisms of xenobiotics. Pharmacol Rev 1995;47:271-330.

23 Stern ST, Bruno MK, Hennig GE, Horton RA, Roberts JC, Cohen SD: Contribution of acetaminophen-cysteine to acetaminophen nephrotoxicity in CD-1 mice: I. Enhancement of acetaminophen nephrotoxicity by acetaminophen-cysteine. Toxicol Appl Pharmacol 2005;202:151-159.

24 Hinchman CA, Ballatori N: Glutathione conjugation and conversion to mercapturic acids can occur as an intrahepatic process. J Toxicol Environ Health 1994;41:387-409.

25 Mathias PI, Bhymer C: Mercapturic acids: recent advances in their determination by liquid chromatography/mass spectrometry and their use in toxicant metabolism studies and in occupational and environmental exposure studies. Biomarkers 2016;21:293-315.

26 Hughey RP, Rankin BB, Elce JS, Curthoys NP. Specificity of a particulate rat renal peptidase and its localization along with other enzymes of mercapturic acid synthesis. Arch Biochem Biophys 1978;186:211-217.

27 Lash LH: Glutathione-dependent bioactivation. Curr Protoc Toxicol 2007;6:1-16.

28 Möller-Hartmann W, Siegers CP: Nephrotoxicity of paracetamol in the rat - mechanistic and therapeutic aspects. J Appl Toxicol 1991;11:141-146.
29 Jones TW, Qin C, Schaeffer VH, Stevens JL: Immunohistochemical localization of glutamine transaminase $\mathrm{K}$, a rat kidney cysteine conjugate beta-lyase, and the relationship to the segment specificity of cysteine conjugate nephrotoxicity. Mol Pharmacol 1988;34:621627

30 MacFarlane M, Foster JR, Gibson GG, King LJ, Lock EA: Cysteine conjugate beta-lyase of rat kidney cytosol: characterization, immunocytochemical localization, and correlation with hexachlorobutadiene nephrotoxicity. Toxicol Appl Pharmacol 1989;98:185-197.

31 Cristofori P, Sauer AV, Trevisan A: Three common pathways of nephrotoxicity induced by halogenated alkenes. Cell Biol Toxicol 2015;31:1-13.

32 Juhanson P, Kepp K, Org E, Veldre G, Kelgo $\mathrm{P}$, Rosenberg M, et al: N-acetyltransferase 8, a positional candidate for blood pressure and renal regulation: resequencing, association and in silico study. BMC Med Genet 2008;9: 25.

33 Tin A, Colantuoni E, Boerwinkle E, Kottgen A, Franceschini N, Astor BC, et al: Using multiple measures for quantitative trait association analyses: application to estimated glomerular filtration rate. J Hum Genet 2013;58: 461-466.

34 Köttgen A, Pattaro C, Böger CA, Fuchsberger C, Olden M, Glazer NL, et al: New loci associated with kidney function and chronic kidney disease. Nat Genet 2010;42:376-384.

35 Omata M, Doke Y, Yamada C, Kawashima K, Sho R, Enomoto K, et al: Hepatocyte nuclear factor- $1 \beta$ induces redifferentiation of dedifferentiated tubular epithelial cells. PLoS One 2016;11:e0154912.

36 Fu J, Zhang H, Zhuang Y, Liu H, Shi Q, Li D, et al: The role of $\mathrm{N}$-acetyltransferase 8 in mesenchymal stem cell-based therapy for liver ischemia/reperfusion injury in rats. PLoS One 2014;9:e103355.

37 Lewis RA, Austen KF: The biologically active leukotrienes. Biosynthesis, metabolism, receptors, functions, and pharmacology. J Clin Invest 1984;73:889-897.

38 Shastri S, McNeill JR, Wilson TW, Poduri R, Kaul C, Gopalakrishnan V: Cysteinyl leukotrienes mediate enhanced vasoconstriction to angiotensin II but not endothelin-1 in SHR. Am J Physiol Hear Circ Physiol 2001;281: H342-H349.

39 Badr KF, Brenner BM, Ichikawa I: Effects of leukotriene D4 on glomerular dynamics in the rat. Am J Physiol 1987;253(2 Pt 2):F239F243.

40 Rosenthal A, Pace-Asciak CR: Potent vasoconstriction of the isolated perfused rat kidney by leukotrienes C4 and D4. Can J Physiol Pharmacol 1983;61:325-328.

41 Leng W, Kuo CG, Qureshi R, Jakschik BA: Role of leukotrienes in vascular changes in the rat mesentery and skin in anaphylaxis. J Immunol 1988;140:2361-2368. 
42 Guo R, Jiang J, Jing Z, Chen Y, Shi Z, Deng B: Cysteinyl leukotriene receptor 1 regulates glucose-stimulated insulin secretion (GSIS). Cell Signal 2018;46:129-134.

43 Stern ST, Bruno MK, Horton RA, Hill DW, Roberts JC, Cohen SD: Contribution of acetaminophen-cysteine to acetaminophen nephrotoxicity II. Possible involvement of the gamma-glutamyl cycle. Toxicol Appl Pharmacol 2005;202:160-171.

44 Dvash E, Har-Tal M, Barak S, Meir O, Rubinstein $\mathrm{M}$ : Leukotriene $\mathrm{C} 4$ is the major trigger of stress-induced oxidative DNA damage. Nat Commun 2015;6:10112.

45 Salauze L, van der Velden C, Lagroye I, Veyret B, Geffard M: Circulating antibodies to cysteinyl catecholamines in amyotrophic lateral sclerosis and Parkinson's disease patients. Amyotroph Lateral Scler Other Motor Neuron Disord 2005;6:226-233.

46 Wang W, Ballatori N: Endogenous glutathione conjugates: occurrence and biological functions. Pharmacol Rev 1998;50:335-356.

47 Haeggström JZ, Funk CD: Lipoxygenase and leukotriene pathways: biochemistry, biology, and roles in disease. Chem Rev 2011;111: 5866-5896.

48 Di Gennaro A, Haeggström JZ: The leukotrienes: immune-modulating lipid mediators of disease. Adv Immunol 2012;116:51-92.

49 Funk CD: Prostaglandins and leukotrienes: advances in eicosanoid biology. Science 2001; 294:1871-1875

50 Samuelsson B, Dahlen SE, Lindgren JA, Rouzer CA, Serhan CN: Leukotrienes and lipoxins: structures, biosynthesis, and biological effects. Science 1987;237:1171-1176.

51 Rafnsson A, Bäck M: Urinary leukotriene E4 is associated with renal function but not with endothelial function in type 2 diabetes. Dis Markers 2013;35:475-480.

52 Petric R, Nicholson DW, Ford-Hutchinson AW: Renal leukotriene C4 synthase: characterization, partial purification and alterations in experimental glomerulonephritis. Biochim Biophys Acta 1995;1254:207-215.

53 Rubinstein M, Dvash E: Leukotrienes and kidney diseases. Curr Opin Nephrol Hypertens 2018;27:42-48.
54 Petric R, Ford-Hutchinson AW: Elevated cysteinyl leukotriene excretion in experimental glomerulonephritis. Kidney Int 1994;46: 1322-1329.

55 Badr KF, Baylis C, Pfeffer JM, Pfeffer MA, Soberman RJ, Lewis RA, et al: Renal and systemic hemodynamic responses to intravenous infusion of leukotriene $\mathrm{C} 4$ in the rat. Circ Res 1984;54:492-499.

56 Assem ES, Abdullah NA: Release of thromboxane $\mathrm{B} 2$ and leukotriene $\mathrm{C} 4$ and reduction in renal perfusion in experimental anaphylactic reaction of isolated guinea pig kidney. Int Arch Allergy Appl Immunol 1987;82:212214.

57 Yang H, Dou Y, Zheng X, Tan Y, Cheng J, Li $\mathrm{L}$, et al: Cysteinyl leukotrienes synthesis is involved in aristolochic acid I-induced apoptosis in renal proximal tubular epithelial cells. Toxicology 2011;287:38-45.

58 Roth DM, Reibel DK, Lefer AM: Altered coronary vascular responsiveness to leukotrienes in alloxan-diabetic rats. Circ Res 1984;54: 388-395.

59 Takiguchi $\mathrm{Y}$, Umemura $\mathrm{K}$, Hashimoto $\mathrm{H}, \mathrm{Na}-$ kashima M: Involvement of thromboxane and leukotriene in arachidonate induced coronary constriction in diabetic rats. Diabetologia 1989;32:337-341.

60 Hardy G, Stanke-Labesque F, Peoc'h M, Hakim A, Devillier P, Caron F, et al: Cysteinyl leukotrienes modulate angiotensin II constrictor effects on aortas from streptozotocininduced diabetic rats. Arterioscler Thromb Vasc Biol 2001;21:1751-1758.

61 Hardy G, Vergnaud S, Lunardi J, Peoc'h M, Bessard G, Stanke-Labesque F: 5-Lipoxygenase expression and activity in aorta from streptozotocin-induced diabetic rats. Prostaglandins Other Lipid Mediat 2005;75:91-103.

62 Hardy G, Boizel R, Bessard J, Cracowski JL, Bessard G, Halimi S, et al: Urinary leukotriene E4 excretion is increased in type 1 diabetic patients: a quantification by liquid chromatography-tandem mass spectrometry. Prostaglandins Other Lipid Mediat 2005;78:291299.

63 Boizel R, Bruttmann G, Benhamou PY, Halimi S, Stanke-Labesque F: Regulation of oxidative stress and inflammation by glycaemic control: evidence for reversible activation of the 5-lipoxygenase pathway in type 1, but not in type 2 diabetes. Diabetologia 2010;53: 2068-2070.

64 Coelho NR, Dias CG, Correia MJ, Grácio P, Serpa J, Monteiro EC, et al: Cysteine oxidative dynamics underlies hypertension and kidney dysfunction induced by chronic intermittent hypoxia; in Gauda E, Monteiro E, Prabhakar N, Wyatt C, Schultz H (eds): Arterial Chemoreceptors - New Directions and Translational Perspectives. Springer, Cham, 2018, vol 1071, pp 83-88.

65 Thompson-Souza GA, Gropillo I, Neves JS: Cysteinyl leukotrienes in eosinophil biology: functional roles and therapeutic perspectives in eosinophilic disorders. Front Med (Lausanne) 2017;4:106.

66 Butterly DW, Spurney RF, Ruiz P, Griffiths R, Albrightson C, Coffman TM: A role for leukotrienes in cyclosporine nephrotoxicity. Kidney Int 2000;57:2586-2593.

67 Daimon M, Sugiyama K, Kameda W, Saitoh T, Oizumi T, Hirata A, et al: Increased urinary levels of pentosidine, pyrraline and acrolein adduct in type 2 diabetes. Endocr J 2003;50: 61-67.

68 Hakonarson H, Thorvaldsson S, Helgadottir A, Gudbjartsson D, Zink F, Andresdottir M, et al: Effects of a 5-lipoxygenase-activating protein inhibitor on biomarkers associated with risk of myocardial infarction: a randomized trial. JAMA 2005;293:2245-2256.

69 Carry M, Korley V, Willerson JT, Weigelt L, Ford-Hutchinson AW, Tagari P: Increased urinary leukotriene excretion in patients with cardiac ischemia. In vivo evidence for 5-lipoxygenase activation. Circulation 1992;85: 230-236.

70 Green SA, Malice MP, Tanaka W, Tozzi CA, Reiss TF: Increase in urinary leukotriene LTE4 levels in acute asthma: correlation with airflow limitation. Thorax 2004;59:100-104.

71 Stanke-Labesque F, Bä M, Lefebvre B, Tamisier R, Baguet JP, Arnol N, et al: Increased urinary leukotriene E4 excretion in obstructive sleep apnea: effects of obesity and hypoxia. J Allergy Clin Immunol 2009;124:364-370. 